\title{
Basis for Defective Proliferation of Peripheral Blood T Cells to Anti-CD2 Antibodies in Primary Sjögren's Syndrome
}

\author{
Roberto Gerli, Alberto Bertotto, * Elisabetta Agea, Luisa Lanfrancone, Cristina Cernetti, \\ Fabrizio Spinozzi, and Pietro Rambotti ${ }^{\dagger}$ \\ Institute of Internal Medicine and *Pediatrics, University of Perugia, Perugia, Italy, I-06100
}

\begin{abstract}
Anti-CD2-induced T cell proliferation was analyzed in the peripheral blood samples of 31 primary and 8 secondary untreated Sjögren's syndrome patients. Anti-CD2-stimulated PBMC proliferation was very low in about one-third of primary Sjögren's syndrome samples, despite the number of CD2 + cells being similar in primary and secondary Sjögren's syndrome and normal PBMC samples. The depressed response to anti-CD2 was mainly found in anti-Ro+/La+ patients. Experiments on purified $T$ cells demonstrated that a defect at the $T$ cell level was responsible for the anti-CD2 unresponsiveness. Cell proliferation failure was associated with poor IL-2 and IL-2 receptor mRNA expression and, consequently, IL-2 and IL-2 receptor synthesis. Since defective anti-CD2-induced mitogenesis could be reversed by phorbol myristate acetate, but not calcium ionophore A23187, it is probably correlated with impaired protein kinase $\mathrm{C}$ activation. Comparison of anti-CD2-triggered PBMC proliferation in treated and untreated patients and a long-term study of nine patients showed that the defect is a stable characteristic in primary Sjögren's syndrome patients, but that it can be reversed by pharmacological immunosuppression. (J. Clin. Invest. 1990. 86:1870-1877.) Key words: lymphocytes • autoantibodies $\bullet$ salivary gland $\bullet$ autoimmunity $\bullet$ monoclonal antibodies
\end{abstract}

\section{Introduction}

Cellular immunity is generally regarded as central to the pathogenesis of primary Sjögren's syndrome (pSS). ${ }^{1}$ Consequently, $T$ cell phenotype and function have been one of the major focuses of experimental studies on this autoimmune disorder during the past few years (1). A number of $\mathrm{T}$ cell abnormalities, thought to be linked to the well known hyperreactivity of $B$ lymphocytes, have been detected in the peripheral blood of patients with pSS (2). However, the basis for this $\mathrm{T}$ cell disregulation is not fully understood.

\section{$\dagger$ Deceased. \\ Address reprint requests to Dr. Roberto Gerli, Istituto di Clinica Medica I, University of Perugia, Policlinico di Monteluce, I-06100, Perugia, Italy. \\ Received for publication 7 February 1990 and in revised form 13 June 1990.}

1. Abbreviations used in this paper: $\mathrm{AC}$, accessory cells; ${ }^{3} \mathrm{H} \mathrm{TdR},{ }^{3} \mathrm{H}$ thymidine; LFA-3, lymphocyte function-associated antigen 3; PKC, protein kinase C; pSS and sSS, primary and secondary Sjögren's syndrome; rIL-1 and rIL-2, recombinant IL-1 and IL-2; Ti, T cell receptor for antigen.

J. Clin. Invest.

(C) The American Society for Clinical Investigation, Inc. 0021-9738/90/12/1870/08 \$2.00

Volume 86, December 1990, 1870-1877
Our knowledge of the mechanisms involved in physiological $T$ cell activation has notably improved with the availability of MAb for specific functional structures of the T cell surface. It is known that the primary pathway for the clonal expansion of $T$ cells occurs by means of antigen recognition by the antigen $\mathrm{T}$ cell receptor $\mathrm{Ti} / \mathrm{CD} 3$ complex (3). In addition, a number of $T$ cell surface molecules, which regulate the activation of $T$ cells, have been identified (3). In particular, the CD2 antigen, originally described as the sheep erythrocyte binding protein, appears to play a crucial role in T cell activation (4). CD2, which is structurally related to its natural ligand lymphocyte function-associated antigen 3 (LFA-3) and distinct from the Ti/CD3 complex, may be regarded as a member of the immunoglobulin superfamily $(3,5)$. At least two epitopes, termed $\mathrm{T} 11_{1}$ and $\mathrm{T} 11_{2}$, have been detected on this molecule in resting $T$ cells. The binding of antibodies to either $T 11_{1}$ or $T 1_{2}$ antigens induces the appearance of a third epitope, called $\mathrm{T}_{1} 1_{3}$. The sequential addition of anti-T $11_{2}$ and anti-T $11_{3}$ antibodies provides a potent $T$ cell mitogenic stimulus, alternative to that offered by antibodies to the Ti/CD3 complex (4). The significance of this alternative $T$ cell activation pathway in physiological and pathological conditions is unclear, but it has been hypothesized that its defective control may render an individual susceptible to pathologic chronic $T$ cell stimulation (6), such as that encountered in several autoimmune disorders (2).

As our preliminary studies revealed a defect in anti-CD2induced PBMC proliferation in patients with pSS (7), we extended our research to investigating both the cellular and molecular mechanisms that underlie the proliferative failure and the relationship between this and the serological features of the disease.

\section{Methods}

Patient population. 38 patients ( 33 female and 5 male, age ranging from 19 to $64 \mathrm{yr}$ ), who fulfilled the Copenhagen criteria for the diagnosis of pSS (8), were included in the study. 31 patients had never been treated, 7 were taking corticosteroids. The results obtained from the treated patient group are reported only when the influence of the therapy on immunological parameters is considered. None fulfilled the criteria for a diagnosis of RA, systemic lupus erythematosus (SLE), progressive systemic sclerosis, or any other known connective tissue disease. 18 aged- and sex-matched healthy subjects acted as controls. Cord blood samples from healthy full-term newborns, collected immediately after birth, were also employed as controls in some experiments. In addition, eight untreated SLE patients with no signs of exocrine glandular involvement and eight patients with SS secondary (sSS) to RA (four patients), SLE (three patients), or progressive systemic sclerosis (one patient) were studied. None of these 16 patients were positive for anti-La antibodies and only 6 , four with SLE and two with SLE plus sSS, were anti-Ro antibody positive.

Serological studies. Antinuclear antibodies were determined by indirect immunofluorescence with Hep-2 human cell line as substrate. Anti-extractable nuclear antigens were detected by counterimmuno- 
electrophoresis, according to Bunn et al. (9), by using an extract of human spleen and rabbit thymus (Pel-Freeze Biologicals, Rogers, AR) as sources of antigens $(10,11)$. Reference sera were kindly provided by Dr. K. B. Elkon, Hospital for Special Surgery, Cornell University, New York.

Cell preparation. PBMC were isolated from heparinized peripheral blood by density gradient centrifugation on Ficoll-Hypaque (Lymphoprep; Nycomed AS, Oslo, Norway) and resuspended in RPMI-1640 supplemented with $10 \%$ FCS, 4 mM L-glutamine, 100 $\mathrm{U} / \mathrm{ml}$ penicillin, and $100 \mu \mathrm{g} / \mathrm{ml}$ streptomycin (complete medium) (Gibco Laboratories, Grand Island, NY). PBMC were separated into sheep red blood cell rosette-enriched $\left(\mathrm{E}^{+}\right)$and rosette-depleted $\left(\mathrm{E}^{-}\right)$ subpopulations as detailed elsewhere $(12) . \mathrm{E}^{-}$-cell suspensions were then irradiated at 3,000 $\mathrm{rad}\left(\mathrm{E}_{\mathrm{x}}^{-}\right)$and used as a source of accessory cells (AC). $\mathrm{E}^{+}$-cell populations were treated with OKM1 MAb (Ortho Pharmaceuticals, Raritan, NJ) plus rabbit complement (Cedarlane, Ornby, Ontario, Canada) to eliminate residual contaminating monocytes. On the basis of their reactivity with anti-CD2 MAb (anti-T11 and anti-T $11_{2}$, kindly supplied by Dr. S. F. Schlossman, Harvard Medical School, Boston, MA), these mononuclear cells were considered purified T cells ( $>97 \%$ with immunofluorescence analysis).

Flow cytometry. IL-2 receptors (IL-2R) were identified by direct immunofluorescence staining with fluoresceinated anti-Tac MAb (Becton Dickinson \& Co., Mountain View, CA). Co-expression of the CD4 and CD45RA antigens on the PBMC surface was revealed by using a fluorescein-conjugated anti-CD4 MAb (T4-FITC; Coulter Immunology, Hialeah, FL) and a phycoerythrin-conjugated antiCD45RA MAb (2H4-RD1; Coulter Immunology). A previously described indirect immunofluorescence technique (12), that used anti$\mathrm{T} 11_{1}, \mathrm{~T} 11_{2}$, and $\mathrm{T} 11_{3} \mathrm{MAb}$ and a fluorescein-conjugated goat anti-mouse $F\left(a b^{\prime}\right)_{2}$ subclass-specific antiserum, that was absorbed with human Ig (Tago, Inc., Burlingame, CA), was employed for recognition of the CD2 surface molecule on resting and activated T cells. Isotypematched MAb that do not react with human cells were used as controls. The stained cells were fixed in 1\% paraformaldehyde in PBS and analyzed by flow cytometry (FACScan; Becton Dickinson \& Co.). Tac+, CD4+, CD45RA+, and CD2+ cells were identified by gating analysis, and fluorescence profiles were obtained for 50,000 cells in each sample. As the percentages of $T 11_{1}$ - and $T 11_{2}$-positive resting $T$ cells overlapped in each sample, only the results obtained with the second $\mathrm{MAb}$ are given.

Cell proliferation assay. PBMC or T cells $\left(5 \times 10^{4} /\right.$ well $)$ were cultured in triplicate in complete medium in 96-well round-bottomed microwell plates (Nunc, Roskilde, Denmark). A combination of anti$\mathrm{T} 11_{2}$ and $-\mathrm{T} 11_{3}$ ascites fluids (gift from Dr. S. F. Schlossman) was used at a final concentration of $1: 800$, which gave a proliferation peak in dilution experiments. PHA (Difco Laboratories Inc., Detroit, MI), anti-CD3 MAb (OKT3; Ortho Pharmaceuticals), phorbol 12-myristate 13-acetate (PMA) (Sigma Chemical Co., St. Louis, MO), human recombinant $\alpha$-IL-1 (rIL-1) (Janssen Chimica, Beerse, Belgium; specific activity: $1.3 \times 10^{7} \mathrm{U} / \mathrm{mg}$ protein), human recombinant IL-2 (rIL-2) (Janssen; specific activity: $9.0 \times 10^{6} \mathrm{U} / \mathrm{mg}$ protein), and calcium ionophore A23187 (free acid; Sigma Chemical Co.) were used at the indicated concentrations. The plates were incubated at $37^{\circ} \mathrm{C}$ for $72 \mathrm{~h}$ in a humidified atmosphere containing $5 \% \mathrm{CO}_{2}$ in air. Cell proliferation was measured by $\left[{ }^{3} \mathrm{H}\right]$ thymidine $\left(\left[{ }^{3} \mathrm{H}\right] \mathrm{TdR}\right)$ incorporation $(0.5 \mu \mathrm{Ci} /$ well; sp act $25 \mathrm{Ci} / \mathrm{mmol}$; Amersham International, Amersham, UK) during the last $6 \mathrm{~h}$ of culture. The samples were harvested on glass-fiber filters, resuspended in a liquid scintillation mixture, and counted in a liquid scintillation spectrometer. Results are expressed as net cpm $\left[{ }^{3} \mathrm{H}\right] \mathrm{TdR}$ incorporation and reflect absolute cpm $\left[{ }^{3} \mathrm{H}\right] \mathrm{TdR}$ uptake minus background cpm (cpm incorporated in the absence of mitogen).

$I L-2$ assay. IL-2 activity was determined in filtered cell culture supernatants after $24 \mathrm{~h}$ stimulation. In brief, after being incubated for 3 $\mathrm{d}$ in complete medium supplemented with $2.5 \times 10^{-5} \mathrm{M}$ 2-mercaptoethanol (Sigma Chemical Co.) and Con A ( $2 \mu \mathrm{g} / \mathrm{ml}$; Miles Laboratories Inc., Naperville, IL), mouse spleen cells were cultured in 96-well flat-bottomed plates (Nunc; $2 \times 10^{4}$ cells/well) in a final volume of 0.2 $\mathrm{ml}$ in the presence or absence of the supernatants $(25 \%)$ under test. Cells were pulsed with $\left[{ }^{3} \mathrm{H}\right] \mathrm{TdR}$ after $18 \mathrm{~h}$ of culture. The cells were harvested $6 \mathrm{~h}$ later and counted as above. All assays were done in triplicate. For each experiment, a standard curve, constructed by using serial dilutions of rIL-2 of known activity, was used to calculate the concentration of IL-2, which was expressed as $U / \mathrm{ml}$ in each culture supernatant. Some supernatants were simultaneously assayed on the IL-2-sensitive mouse cell line CTLL (13). As both assays yielded similar results in terms of $\mathrm{U} / \mathrm{ml}$, only the data for murine splenocytes are given.

RNA preparation. Total cellular RNA was isolated by the guanidium/cesium chloride method (14). Briefly, $20 \times 10^{6}$ PBMC were stimulated for 8 or $24 \mathrm{~h}$ with anti-CD2 MAb or PHA. The cells from fresh and stimulated samples were then stirred with a Vortex mixer in a 4-M guanidine isothiocyanate solution and the mixture layered onto a 5.7-M cesium chloride cushion and centrifuged overnight in a SW41 rotor (Beckman Instruments Inc., Palo Alto, CA) at 31,000 rpm. The RNA pellet was redissolved in water, phenol extracted twice, and ethanol precipitated.

Northern blot hybridization and quantification of gene expression. Total RNA ( $15 \mu \mathrm{g} /$ lane) was analyzed by electrophoresis through $1.0 \%$ agarose gels containing $2.2 \mathrm{M}$ formaldehyde. The size-fractionated RNA was then transferred to nitrocellulose by using a solution of $3 \mathrm{M}$ $\mathrm{NaCl}$ and $0.3 \mathrm{M} \mathrm{Na}$ citrate and the filters hybridized to ${ }^{32} \mathrm{P}$-labeled DNA probes at a specific activity of $1-3 \times 10^{8} \mathrm{cpm} / \mu \mathrm{g}$ DNA (14). The IL-2 and IL-2R probes used in this study were of human origin (a gift from Dr. G. H. Reem, New York University Medical Center, New York). The relative intensity of the RNA transcript signal on the Northern blots was determined by densitometry. The amount of RNA loaded in each lane was normalized by hybridizing the Northern blots to a probe that is transcribed at the same level in all the cells (glyceraldehyde-3-phosphate-dehydrogenase gene) (data not shown).

Statistical analysis. Due to the nonnormal distribution of the data Kruskall-Wallis analysis of the variance was used for statistical evaluation of the results.

\section{Results}

Expression of surface CD2 molecule on PBMC. The percentages of CD2+ cells in pSS (mean \pm SEM: $69.7 \pm 4 \%$ ), sSS (71.8 \pm 4$)$, SLE (67.8 \pm 6$)$, and control (72.5 \pm 3$)$ PBMC samples were comparable $(P=\mathrm{NS})$. In addition, the molecule was expressed with similar intensity on the positive cells of the four groups of samples, since the cytofluorographic profiles for the anti-CD2 overlapped (data not shown).

Activation of PBMC. The PBMC blastogenic response to PHA (final dilution 1:100) was similar in pSS (mean \pm SEM: $64,456 \pm 22,765 \mathrm{cpm}), \mathrm{sSS}(69,582 \pm 24,699 ; P=\mathrm{NS})$, and control $(73,121 \pm 21,003 ; P=\mathrm{NS})$ samples. Anti-CD3 response (final dilution $25 \mathrm{ng} / \mathrm{ml}$ ) was only slightly lower in pSS $(12,459 \pm 6,631)$ than in sSS $(18,399 \pm 4,498 ; P<0.05)$ and controls $(16,593 \pm 4,621 ; P<0.05)$. In contrast, anti-CD2-induced mean proliferation was markedly lower in pSS $(27,839 \pm 25,766)$ than in either sSS $(57,849 \pm 27,127 ; P$ $<0.001)$, SLE $(69,942 \pm 31,773 ; P<0.001)$, or control PBMC samples $(43,551 \pm 15,466 ; P<0.001)$. The reduced proliferation was not influenced by changes in incubation time or MAb concentration (Fig. 1). There was no direct relationship between hyporesponsiveness to anti-CD2 and antinuclear antibody titers or immunofluorescence pattern. However, when pSS patients were subdivided into three groups according to anti-extractable nuclear antigen positivity, i.e., Ro-/La-, $\mathrm{Ro}+/ \mathrm{La}-, \mathrm{Ro}+/ \mathrm{La}+$, proliferation was found to be within the normal range in the $\mathrm{Ro}-/ \mathrm{La}-$ group $(P=\mathrm{NS})$, slightly but not significantly decreased in $\mathrm{Ro}+/ \mathrm{La}-$ patients $(P=\mathrm{NS})$, and 

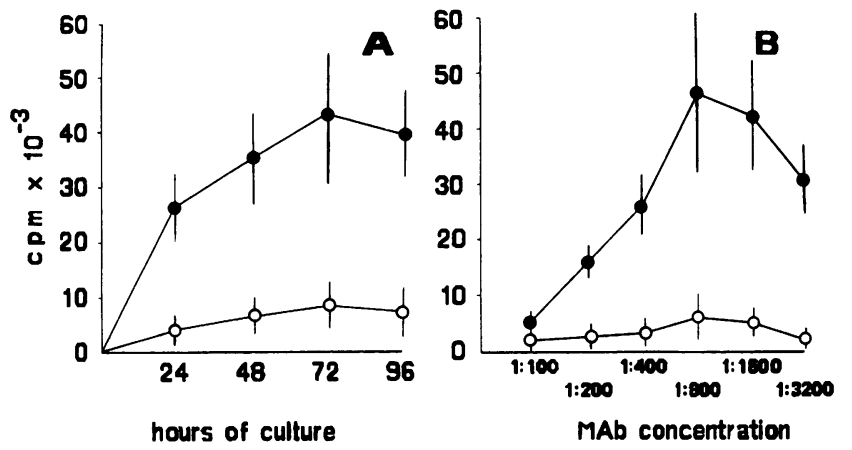

Figure 1. Anti-CD2-induced proliferation of three unresponsive pSS (white circles) and three normal control PBMC samples (black circles) (mean \pm SEM), according to time of culture $(A)$ and anti-CD2 concentration $(B)$.

markedly reduced in Ro+/La+ subjects $(P<0.001)$ (Fig. 2). There was no difference in the CD2 molecule expression of hypo- and normo-reactive pSS samples (data not shown).

Anti-CD2 T-lymphocyte activation in T cell and T-plus $A C$ cultures. Despite the fact that the $\mathrm{T}$ cell activation pathway via the $\mathrm{CD} 2$ molecule has been reported to be monocyte independent, our recent studies on immature human cord cells have demonstrated that monocytes can exert an influence on CD2triggered $T$ cell activation (15). For this reason, experiments were designed to establish whether an inhibitory effect or a failure of AC was responsible for the mitogenic defect in pSS PBMC. As Fig. 3 shows, purified T cells from unresponsive pSS PBMC samples did not respond to anti-CD2 stimulation, whereas those from normal subjects did, thereby suggesting that a functional defect at the $T$ cell level was responsible for the faulty pSS PBMC proliferation. Moreover, since the addition of either pSS or normal AC to anti-CD2-stimulated patient $T$ cell cultures did not modify their impaired proliferation, and the mixing of patient $\mathrm{AC}$ to normal $\mathrm{T}$ cell cultures had no effect on their response to the anti-CD2 stimulus, it would seem that patient $\mathrm{AC}$ are functionally normal and do not exert any significant inhibitory effect.

$I L-2$ production. As $\mathrm{T}$ cell activation via the $\mathrm{CD} 2$ molecule is regulated by an IL-2-dependent autocrine process, the in

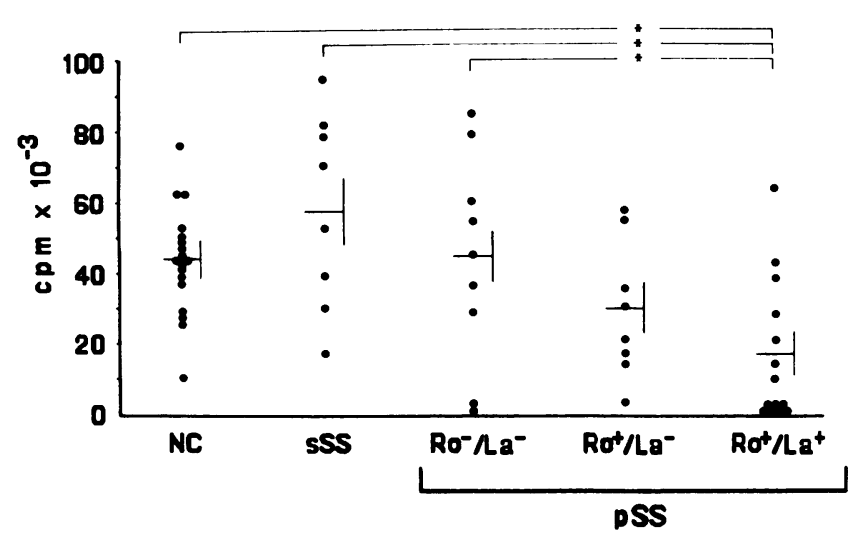

Figure 2. Anti-CD2-induced PBMC proliferation in normal control $(N C)$ and sSS subjects and pSS patients subdivided according to anti$\mathrm{Ro} / \mathrm{La}$ positivity. Horizontal and vertical bars indicate mean $\pm \mathrm{SEM}$. ${ }^{*} P<0.001$.

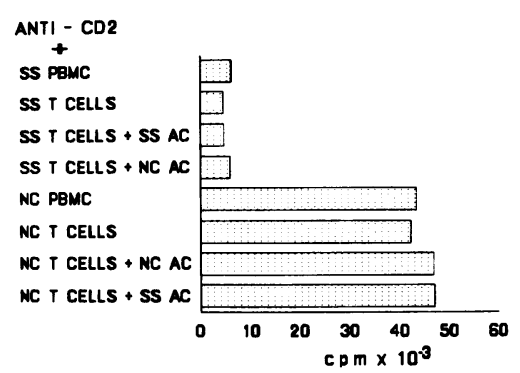

Figure 3. Proliferation in $T$ cell cultures and $T$ cell + AC co-cultures from primary SS patients and normal control subjects. The results are from a single experiment representative of four separate experiments. $50 \% \mathrm{AC}$ were added to $T$ cells in the co-culture experiments.

vitro production of this cytokine by anti-CD2 triggered PBMC was analyzed to better define the mechanisms implicated in the faulty proliferation of pSS cells. As shown in Table I, no IL-2 was detected in supernatants of patient PBMC or T-cell samples that responded poorly to anti-CD2 triggering (Experiment 1), whereas significant amounts of this lymphokine were found in both normoresponsive pSS and control samples (Experiment 2).

$\mathrm{T11}_{3}$-antigen expression on PBMC surface after anti-T11 ${ }_{2}$ stimulation. To test the capacity of the anti-T $11_{2}$ MAb to induce the expression of the $\mathrm{T}_{1} 1_{3}$ membrane antigen, it was added alone to three anti-CD2-unresponsive pSS and three control PBMC samples. The results showed that the anti-T1 $11_{2}$ MAb induced an equal expression intensity of $\mathrm{T}_{1} 1_{3}$ on a similar number of $T$ cells in both pSS and control PBMC samples (data not shown).

Membrane $I L-2 R$ expression. The expression of the IL-2R, as recognized by the Tac MAb, was evaluated in both antiCD2- and PHA-stimulated pSS and control PBMC. Patient samples with a weak response to anti-CD2-stimulation expressed low levels of IL-2R (Table II). In contrast, IL-2R expression was unimpaired in pSS samples with normal antiCD2-induced proliferation, as well as in PHA-stimulated normal and pSS cultures. Identical results were obtained when anti-CD2-induced $\mathrm{T}$ cell cultures were analyzed.

Transcription of $I L-2$ and $I L-2 R$ genes. To determine whether the failure in IL-2 and IL-2R synthesis was at the transcriptional or translational level, Northern blots were performed on resting and both PHA- and anti-CD2-stimulated PBMC in two anti-CD2-unresponsive pSS and two normal control samples. The faulty cell proliferation and absence of IL-2 production in patient samples were associated with lack

Table I. IL-2 Production (U/ml) by PHA or Anti-CD2Stimulated PBMC and T Cells from Patients pSS and Normal Controls (NC)

\begin{tabular}{lccccc}
\hline & \multicolumn{2}{c}{ Experiment 1 } & & \multicolumn{2}{c}{ Experiment 2 } \\
\cline { 2 - 3 } \cline { 5 - 6 } \multicolumn{1}{c}{ Stimulus } & pSS & NC & & pSS & NC \\
\hline PBMC + medium & $<0.1(0.4)^{*}$ & $<0.1(0.3)$ & & $<0.1(0.5)$ & $<0.1(0.4)$ \\
PBMC + PHA & $6.0(61.5)$ & $7.5(89.3)$ & & $7.7(79.4)$ & $8.1(90.0)$ \\
PBMC + anti-CD2 & $<0.1(2.6)$ & $6.8(42.9)$ & & $7.0(39.5)$ & $7.1(44.3)$ \\
T cells + medium & $<0.1(0.4)$ & $<0.1(0.3)$ & & $<0.1(0.4)$ & $<0.1(0.5)$ \\
T cells + anti-CD2 & $<0.1(1.1)$ & $6.1(35.5)$ & & $6.9(37.3)$ & $7.0(41.9)$
\end{tabular}

Two representative experiments of six are shown. Experiment 1 refers to an anti-CD2-unresponsive and experiment 2 to an anti-CD2-responsive pSS PBMC sample. ${ }^{*} \mathrm{cpm} \times 10^{-3} ;{ }^{\ddagger}$ PHA was used at a final dilution of $1: 100$ 
Table II. Percentages of IL-2R Expressing ( $\left.\mathrm{Tac}^{+}\right)$Cells in PBMC and T cell Cultures from pSS Patients and Normal Controls (NC) after 3-d Stimulation with PHA or Anti-CD2

\begin{tabular}{lccllll}
\hline & \multicolumn{2}{c}{ Experiment 1 } & & \multicolumn{2}{c}{ Experiment 2 } \\
\cline { 2 - 3 } \cline { 5 - 6 } \multicolumn{1}{c}{ Stimulus } & pSS & \multicolumn{1}{c}{ NC } & & pSS & NC \\
\hline PBMC + medium & $<5 \%(0.3)^{*}$ & $<5 \%(0.5)$ & & $<5 \%(0.4)$ & $<5 \%(0.4)$ \\
PBMC + PHA & $62 \%(54.4)$ & $59 \%(78.3)$ & & $55 \%(57.9)$ & $64 \%(62.4)$ \\
PBMC + anti-CD2 & $6 \%(1.4)$ & $58 \%(44.3)$ & & $54 \%(38.4)$ & $60 \%(50.9)$ \\
T cells + medium & $<5 \%(0.3)$ & $<5 \%(0.4)$ & & $<5 \%(0.6)$ & $<5 \%(0.4)$ \\
T cells + anti-CD2 & $<5 \%(0.8)$ & $74 \%(39.4)$ & & $61 \%(36.4)$ & $70 \%(49.7)$
\end{tabular}

Two representative experiments of six are shown. Experiment 1 refers to an anti-CD2-unresponsive and Experiment 2 to an anti-CD2-responsive pSS PBMC sample. ${ }^{*} \mathrm{cpm} \times 10^{-3} ;{ }^{\ddagger} \mathrm{PHA}$ was used at a final dilution of $1: 100$.

of IL-2 mRNA expression, since anti-CD2-induced pSS PBMC, unlike normal and patient PBMC stimulated for two days with PHA, did not display the IL-2 hybridizing band (Fig. $4 \mathrm{~A}$ ). Northern blot analysis also indicated that the anti-CD2 stimulus was unable to induce IL-2R-specific mRNA in patient samples (Fig. $4 \mathrm{~B}$ ). These data exclude that a posttranscriptional defect could have been responsible for the fault in IL-2R expression and IL-2 synthesis and secretion.

Effect of exogenous $r I L-1$ and $r I L-2$ on anti-CD2-induced $T$-cell activation. An optimal concentration $(5 \mathrm{U} / \mathrm{ml})$ of rIL-1 or rIL-2 induced no proliferation in both unstimulated pSS and control T-cell samples (Table III). Addition of rIL-2, which enhanced the anti-CD2-mediated proliferation of control cells, failed to improve the poor response of pSS T-cell cultures to anti-CD2 triggering. The addition of rIL-1 to pSS and control anti-CD2-stimulated $\mathrm{T}$ cells had no effect on either.

Effect of calcium ionophore A23187 or PMA on anti-CD2induced $T$ cell activation. Because our results pointed to an impairment in the early transductional events of anti-CD2pulsed $\mathrm{T}$ cell activation, we performed $\mathrm{T}$ cell culture experi-

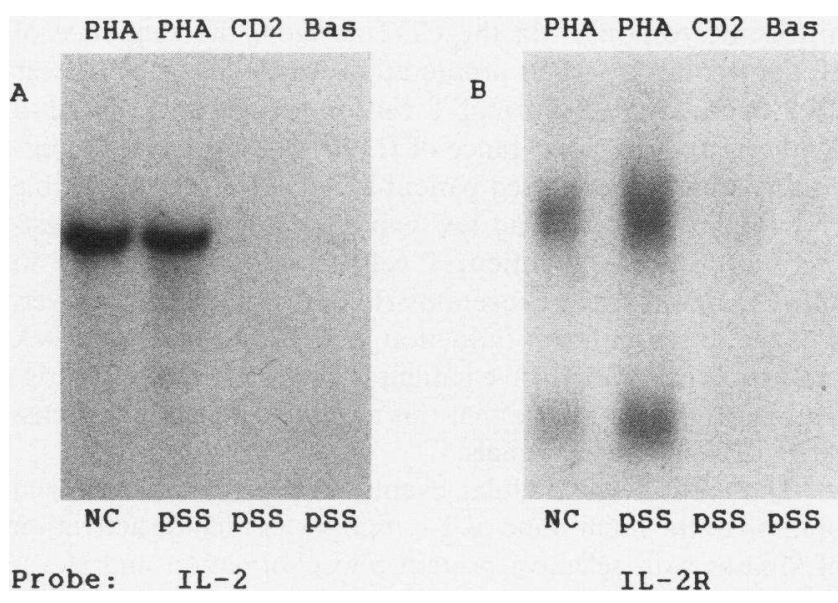

Figure 4. IL-2 $(A)$ and IL-2R $(B)$ mRNA expression in pSS and normal control $(N C)$ PBMC. The results obtained in a representative experiment of two are reported. $15 \mu \mathrm{g}$ of total cellular RNA were run in each lane. The first two lanes refer to PHA-stimulated NC and pSS PBMC, the third to anti-CD2-stimulated pSS PBMC and the last to unstimulated (bas) pSS PBMC. The anti-CD2-induced proliferation value was $48,045 \mathrm{cpm}$ for NC and $1,786 \mathrm{cpm}$ for pSS samples.
Table III. Effects of Exogenous rIL-1 and rIL-2 on Anti-CD2Stimulated T Cell Proliferation in pSS and Normal Control (NC) Samples

\begin{tabular}{llrrrr}
\hline & \multicolumn{2}{c}{ Experiment 1 } & & \multicolumn{2}{c}{ Experiment 2 } \\
\cline { 2 - 3 } \cline { 6 - 6 } \multicolumn{1}{c}{ Stimulus } & pSS & NC & & pSS & NC \\
\hline Medium & $0.3^{*}$ & 0.5 & & 0.4 & 0.7 \\
Anti-CD2 & 3.4 & 51.5 & & 39.2 & 47.7 \\
rIL-1 $^{\ddagger}$ & 0.4 & 0.6 & & 0.4 & 0.9 \\
Anti-CD2 + rIL-1 $^{*}$ & 3.9 & 56.5 & & 38.3 & 49.6 \\
rIL-2 & 0.9 & 0.8 & & 2.0 & 1.4 \\
Anti-CD2 + rIL-2 & 3.9 & 69.8 & & 50.1 & 64.7 \\
& & & & \\
\hline
\end{tabular}

Two representative experiments of five are shown. Experiment 1 refers to an anti-CD2-unresponsive and Experiment 2 to an antiCD2-responsive pSS PBMC sample. ${ }^{*} \mathrm{cpm} \times 10^{-3}$; ${ }^{\ddagger} \mathrm{rIL}-1$ and ${ }^{\S}$ rIL-2 were used at the final concentration of $5 \mathrm{U} / \mathrm{ml}$.

ments with anti-CD2 plus either PMA or calcium ionophore A23187 to explore the early intracellular signals that lead to activation of protein kinase C (PKC) and increase in cytoplasmic calcium level. Table IV shows that increased concentrations of calcium ionophore exerted no influence on the poor patient $\mathrm{T}$ cell response to anti-CD2 activation, despite the fact that this reagent is known to invert defective anti-CD2-induced proliferation of cord T cells (15). In contrast, pSS T cell samples that failed to respond to anti-CD2 alone, proliferated well when PMA (1-2 ng/ml) was added to the cultures (Table V).

Influence of immunosuppressive therapy on PBMC activation in pSS patients. As corticosteroids are known to exert a marked inhibitory influence on the immune system, the anti$\mathrm{CD} 2$-activated proliferation of treated and untreated patients was compared (Fig. 5). Interestingly, proliferation of pSS PBMC, which was markedly depressed during treatment, was above control levels in the group of patients who had terminated immunosuppressive therapy at least one month before the study was begun. Furthermore, a longitudinal study in six treated and three untreated pSS patients has shown not only that therapy can cause the low anti-CD2-stimulated PBMC

Table IV. Effects of Calcium Ionophore A23187 on Anti-CD2Stimulated T Cells from pSS and Cord (C) Blood Samples

\begin{tabular}{cccccr}
\hline & \multicolumn{2}{c}{ Experiment 1 } & & \multicolumn{2}{c}{ Experiment 2 } \\
\cline { 2 - 3 } \cline { 5 - 6 } A23187 & pSS & $\mathrm{C}$ & & $\mathrm{pSS}$ & $\mathrm{C}$ \\
\hline$n g / m l$ & & & & \\
0 & $2.3^{*}$ & 5.4 & & & \\
12.5 & 3.1 & 5.1 & 60.8 & 5.9 \\
25 & 2.9 & 12.8 & 63.9 & 10.7 \\
50 & 3.3 & 49.5 & 60.8 & 40.4 \\
100 & 4.0 & 54.8 & 48.7 & 38.7 \\
200 & 1.9 & 12.4 & 12.2 & 6.1 \\
& & & &
\end{tabular}

Two experiments of four are shown. Experiment 1 refers to an antiCD2-unresponsive and Experiment 2 to an anti-CD2-responsive pSS PBMC sample. ${ }^{*} \mathrm{cpm} \times 10^{-3}$. 
Table V. Effects of PMA on Anti-CD2-Stimulated T Cells from pSS Patients and Normal Controls (NC)

\begin{tabular}{lrrrr} 
& \multicolumn{2}{c}{ Experiment 1 } & & \multicolumn{2}{c}{ Experiment 2 } \\
\cline { 2 - 5 } PMA & $\mathrm{pSS}$ & $\mathrm{NC}$ & $\mathrm{pSS}$ & $\mathrm{NC}$ \\
\hline$n g / m l$ & & & & \\
0 & $2.2^{*}$ & 39.8 & 31.4 & 49.7 \\
0.1 & 3.1 & 42.2 & 34.9 & 54.6 \\
1 & 48.7 & 44.5 & 39.1 & 47.6 \\
2 & 60.3 & 40.8 & 56.2 & 50.4 \\
5 & 30.8 & 18.7 & 21.7 & 33.6 \\
10 & 8.6 & 5.9 & 20.8 & 17.8 \\
& & & &
\end{tabular}

Two representative experiments of four are shown. Experiment 1 refers to an anti-CD2-unresponsive and Experiment 2 to an antiCD2-responsive pSS PBMC sample. ${ }^{*} \mathrm{cpm} \times 10^{-3}$.

mitogenesis to reverse, but also that the primitive proliferation defect is a stable feature in untreated patients (Fig. 6).

Percentage of CD4 + cells and their subsets in PBMC samples from controls and untreated and treated $p S S$ patients. To search a relationship between phenotypic and functional characteristics of PBMC in pSS patients, the percentages of the total CD4+ and CD45RA positive and negative CD4+ cell populations were evaluated. There were no differences in the proportions of the three subsets in normal controls and pSS patients studied before and 1-6 mo after terminating corticosteroids (Fig. 7). In addition, there was no strict correlation between the number of $\mathrm{CD} 4+, \mathrm{CD} 4+\mathrm{CD} 45 \mathrm{RA}+$, or CD4+CD45R A- cells and responsiveness of pSS samples to anti-CD2 MAb either before or after immunosuppressive therapy (data not shown).

\section{Discussion}

Since a significant body of evidence suggests that cellular immunity is intimately involved in the pathogenesis of pSS (1), the study of the activation processes of peripheral blood $T$ lymphocytes should add to our understanding of the immunoregulatory abnormalities encountered in this autoimmune disorder (2).

$\mathrm{T}$ lymphocytes are known to be physiologically activated by various stimuli directed against either the $\mathrm{Ti} / \mathrm{CD} 3$ complex or the CD2 molecule (3). While the molecular basis and the

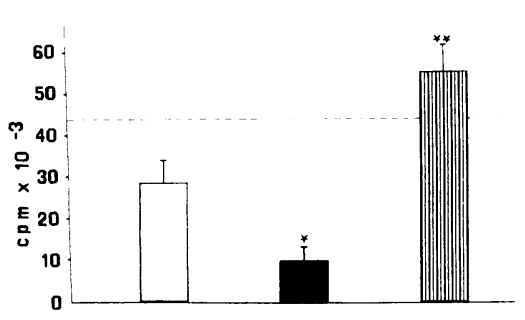

Figure 5. Anti-CD2-induced PBMC proliferation in 18 normal controls (horizontal broken line indicates the mean proliferation) compared with that of 31 untreated (white column) and 20 treated pSS patients, eleven tested

during treatment (black column) and nine from 1 to 6 mo after stopping (shaded column) immunosuppressive therapy. ${ }^{*} P<0.001$ vs. normal controls; ${ }^{* *} P<0.001$ vs. untreated patients and patients tested during therapy. biological significance of $\mathrm{T}$ cell activation via the $\mathrm{CD} 3$ antigen have been reasonably well defined, we know little about the physiological role played by the interaction of $\mathrm{CD} 2$ with its homologous cell surface-associated ligand LFA-3 (5). It has been postulated that $\mathrm{CD} 2$ regulates an antigen-independent activation pathway (4) or that the signals delivered via $\mathrm{CD} 2$ are an integral part of the antigen-specific pathway (16). Interestingly, previous studies have shown not only a requirement for the Ti/CD3 complex in CD2 signaling (16), but also a physical association between the CD3 and CD2 molecules (17).

Although we found, like others $(7,18)$, that the cell proliferation induced via the CD3 structure is only moderately decreased in PBMC samples from pSS patients, CD2-activated proliferation is markedly defective in many. In particular, we found a severe depression in anti-CD2-mediated proliferation in about one-third of pSS samples, irrespective of the antibody concentration or culture time.

Despite the fact that $\mathrm{T}$ cell proliferation via the $\mathrm{CD} 2$ molecule is usually thought to occur in the absence of both IL-1 and AC (4), both have been recently reported to exert a regulatory influence on anti-CD2-mediated activation of cord T lymphocytes (15). We, therefore, carried out experiments to test whether impairment of, or suppression by, antigen-presenting cells could be responsible for the reduced pSS PBMC proliferation and demonstrated that, when pSS AC are mixed with normal $\mathrm{T}$ cells, they do not inhibit anti-CD2-mediated activation. The fact that anti-CD2 alone, or combined with rIL-1 or normal AC, failed to significantly trigger mitogenesis of pSS T cells, is evidence that the depressed proliferation is the result of a defect at the T cell level.

An obvious explanation for the decreased anti-CD2-activated proliferation of patient $T$ cells would seem to be reduced membrane expression of the CD2 molecule. However, we showed that neither low numbers of CD2+ cells within the pSS PBMC population nor deficient $T$ cell surface expression of the $\mathrm{CD} 2$ receptor accounted for the diminished proliferation, since the percentage of $\mathrm{CD} 2+$ cells, peak and mean fluorescence intensity, were similar in normal and pSS PBMC samples.

In an attempt to better comprehend the basis of the faulty mitogenic response via the $\mathrm{CD} 2$ antigen, the sequence of events leading to $T$ cell proliferation was analyzed. Whereas CD2 stimulation of normal T cells is accompanied by IL-2 synthesis and the appearance of IL-2R (4), defectively proliferating anti-CD2-triggered patient $\mathrm{PBMC}$ produced negligible amounts of IL-2 and had low expression of IL-2R. Interestingly, unresponsive patient $T$ cells remained refractory to anti-CD2 even when exogenous rIL-2 was added. Moreover, the lack of a significant induction of IL-2 and IL-2R mRNA expression in unresponsive patient PBMC after anti-CD2 triggering provides evidence that this stimulus is unable to transduce early activation signals.

The earliest intracellular events after antigen or mitogen binding to the membrane of $\mathrm{T}$ lymphocytes include activation of kinases with selective protein phosphorylation and elevation of cytoplasmic calcium concentrations (19-21). Specifically, stimulation of the $\mathrm{CD} 2$ molecule by soluble MAb results in a rapid rise in cytoplasmic $\mathrm{Ca}^{2+}$, which occurs as a result of phosphatidyl-inositol metabolism. Breakdown of inositol phospholipids is followed by the generation of inositol triphosphate, the putative mobilizer of $\mathrm{Ca}^{2+}$ from the intracellular membrane pool, and 1,2-diacylglycerol, a natural activator 


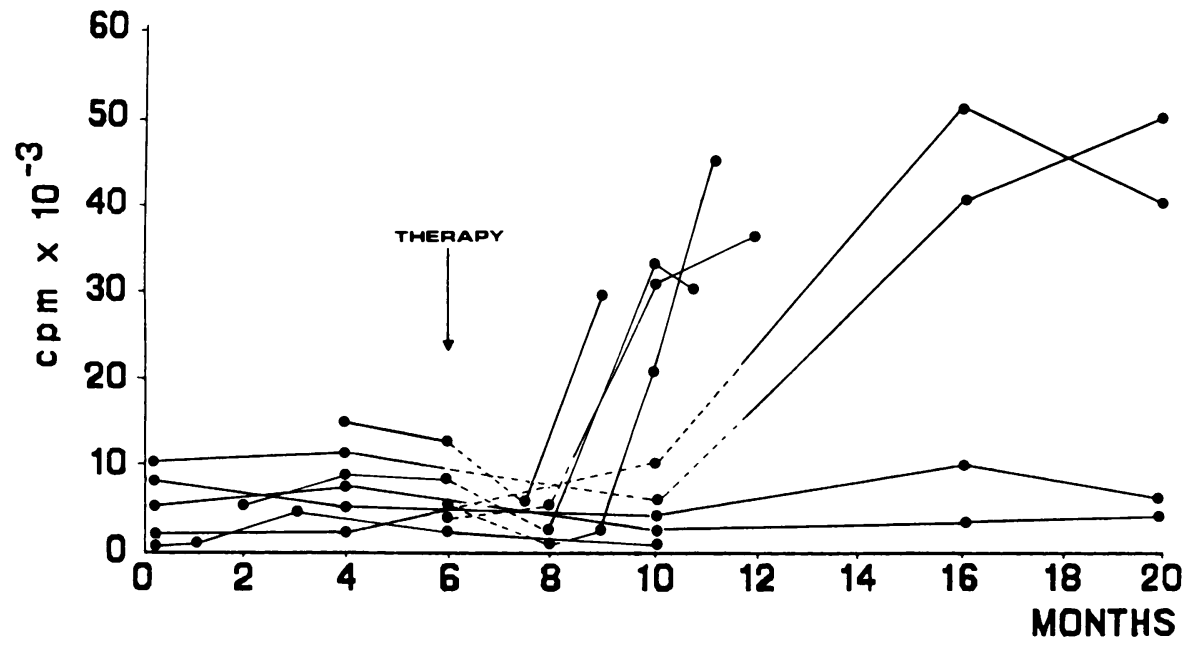

Figure 6. Longitudinal study of anti-CD2induced PBMC proliferation in nine pSS patients, three untreated, and six tested before, during, and after stopping corticosteroid therapy. Broken lines indicate treatment period. of PKC (22). It is known that the action of inositol trisphosphate may be mimicked by $\mathrm{A} 23187, \mathrm{a} \mathrm{Ca}^{2+}$ channel opening antibiotic that induces an influx of $\mathrm{Ca}^{2+}$ from the extracellular environment into cell cytoplasm (23). On the other hand, PKC can also be directly activated in vitro by PMA (24). In our experiments, the combination of anti-CD2 with PMA, but not with A23187, evoked good proliferation of patient $\mathrm{T}$ cells. Therefore, it could be speculated that the unresponsiveness of pSS $\mathrm{T}$ cells to anti-CD2 is not secondary to a defect in transmembrane transduction of the activation signal, but rather, related to an impairment in posttransductional PKC triggering, which would then lead to a failure in IL-2 and IL-2R mRNA specific induction, IL-2 production, and IL-2R expression and, consequently, cell proliferation.

The distinctly different results we obtained in treated and untreated pSS patients confirm that immunosuppressive therapy is able to alter $T$ lymphocyte function and obscure their pathogenetic role (24). Our 18-mo followup study on 6 treated and 3 untreated subjects with pSS seems to indicate that, when present, defective anti-CD2-mediated $\mathrm{T}$ cell proliferation is a stable characteristic, but that immunosuppressive therapy is able to restore $T$ cell function. The persistence of this immunological defect in the absence of treatment and its reversibility with therapy recalls the failure of $T$ cell activation via the CD5 molecule previously described in the peripheral blood of pSS patients (18). However, despite the fact that a number of antiCD5 MAb have been demonstrated to exert a co-stimulatory effect on murine $(25,26)$ and human $(27) \mathrm{T}$ cells activated by suboptimal doses of PHA or anti-CD3, the relationship between the CD2 and CD5 structures in activation pathways of

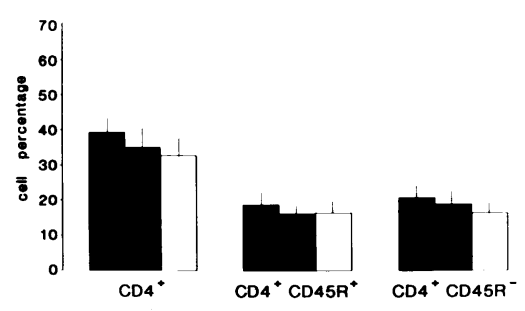

Figure 7. Percentage of CD4+, CD4+CD45$\mathrm{RA}+$, and CD4+CD45RA - cells in normal controls (shaded column), untreated pSS patients (black column), and pSS patients studied 1-6 mo after stopping immunosuppressive therapy (white column). $P=$ NS. both normal and pSS T lymphocytes remains unclear and requires further investigations.

As CD4+CD45RA+ PBL appear to respond better to anti-CD2 triggering than their reciprocal CD4+CD45RAcell subset (28), low numbers of these may be responsible for the faulty anti-CD2-induced $T$ cell activation. However, our results showed similar CD45RA antigen expression within CD4+ cell population in control and pSS patients, before, during, and after treatment. The fact that these data disagree with previous reports, showing a reduced CD4+CD45RA+ cell percentage in pSS (29), may be explained by different selection and/or different serological characteristics of the patients.

Because $\mathrm{T}$ cell dysregulation is feature common to several autoimmune diseases $(2,30,31)$, the present findings may lack specificity. However, they do seem to show that defective anti$\mathrm{CD} 2$ proliferation is a characteristic of primary, but not secondary, SS. In addition, our data show that anti-CD2-mediated proliferation of blood $\mathrm{T}$ lymphocytes is greater in untreated patients with SLE than in pSS subjects. Finally, we demonstrated that defective $T$ cell activation via CD2 is mainly characteristic of a subgroup of pSS patients who have serological evidence of anti-La autoantibodies, which apparently represent the most reliable marker of this autoimmune disorder and define a subset of patients with more severe disease involvement $(1,32,33)$.

The sum total of these observations should help to clarify the biological significance of the $T$ cell dysfunction encountered in the peripheral blood of these patients. Primary SS, unlike systemic lupus erythematosus (SLE), is an autoimmune disease in which the main cellular immune activity is expressed at the level of target organs, i.e., exocrine glands, as demonstrated by the prevalence of $T$ cells in glandular infiltrates (34-36). Strong differences in functional activity of inflammatory site and peripheral blood $\mathrm{T}$ lymphocytes have been previously described in patients with pSS. Fox et al. (37) found that PHA-induced IL-2 synthesis was profoundly depressed in the PBL, in $\sim 25 \%$ of their pSS patients, while IL-2 production by the salivary gland lymphocytes of the same patients was normal. The peripheral blood and glandular lymphocytes of pSS subjects have also been reported to respond differently to exogenous rIL-2 (7). It could be postulated, therefore, that the patient-to-patient fluctuations in the re- 
sponse of peripheral blood $\mathrm{T}$ cells to anti-CD2 seen in pSS reflect different degrees of $T$ cell involvement at the target organs.

A relationship between PBMC unresponsiveness to soluble antigens and high intensity lymphocyte infiltration at the site of inflammation has been documented in patients with RA, who also have inversely related peripheral blood and synovial $\mathrm{T}$ cell subset ratios (38-40). This apparently paradoxical relationship, which is consistent with our findings in other immune-mediated disorders $(41,42)$, suggests that blood $\mathrm{T}$ cell dysfunction and trafficking of $T$ lymphocytes between peripheral blood and inflammation sites are interrelated phenomena. It could also be pertinent to understanding the mechanism underlying the improvement in $\mathrm{T}$ cell function induced by immunosuppressive therapy, which is known to reduce $T$ cell infiltration in exocrine glands (1). According to this theory, the association between unresponsiveness to anti-CD2 and the presence of anti-La autoantibodies in patients' blood would be accounted for by the fact that salivary gland infiltration by $T$ cells is usually more intense in anti-La-positive than in antiLa-negative pSS patients (unpublished observations).

In conclusion, our data seem to imply that pSS comprises a wide spectrum of conditions in which polar subsets can be defined on the basis of their immunological, serological, and hystopathological features. They also provide clues to the pathogenesis of pSS and have potential application in the monitoring of therapy in this disorder.

\section{Acknowledgments}

We wish to thank Dr. Stuart F. Schlossman, Dana-Farber Cancer Institute, Harvard Medical School, Boston, MA, for the very useful discussion on the results and for providing the anti-T $11_{1}, \mathrm{~T} 11_{2}$, and $\mathrm{T}_{11}{ }_{3}$ monoclonal antibodies, and Dr. S. Bombardieri and Dr. C. Vitali, Rheumatology Unit, University of Pisa, Italy, for providing blood samples from four pSS patients.

\section{References}

1. Talal, N., and H. M. Moutsopoulos. 1987. Sjögren's Syndrome. Springer-Verlag, Heidelberger, West Germany. 295 pp.

2. Gupta, S., and N. Talal. 1985. Immunology of Rheumatic Diseases. Plenum Publishing Corp., New York. 809 pp.

3. Rudd, C. E., P. Anderson, C. Morimoto, M. Streuli, and S. F. Schlossman. 1989. Molecular interactions, T-cell subsets and a role of the CD4/CD8:p56 ${ }^{\text {1ck }}$ complex in human T-cell activation. Immunol. Rev. 111:225-266.

4. Meuer, S. C., R. E. Hussey, M. Fabbi, D. Fox, O. Acuto, A. Fitzgerald, S. C. Hodgdon, J. P. Protentis, S. F. Schlossman, and E. L. Reinherz. 1984. An alternative pathway of T-cell activation: a functional role for the $50 \mathrm{kd} \mathrm{T11}$ sheep erythrocyte receptor protein. Cell. 36:897-906.

5. Anderson, P., C. Morimoto, J. B. Breitmeyer, and S. F. Schlossman. 1988. Regulatory interactions between members of the immunoglobulin superfamily. Immunol. Today. 9:199-203.

6. Fox, D. A., S. F. Schlossman, and E. L. Reinherz. Regulation of the alternative pathway of $\mathrm{T}$ cell activation by anti-CD3 monoclonal antibodies. J. Immunol. 136:1945-1950.

7. Gerli, R., A. Bertotto, C. Cernetti, E. Agea, S. Crupi, C. Arcangeli, F. Spinozzi, R. Galandrini, and P. Rambotti. 1989. Anti-CD3 and anti-CD2-induced T-cell activation in primary Sjögren's syndrome. Clin. Exp. Rheumatol. 7/3(Suppl):129-134.

8. Manthorpe, R., P. Oxholm, J. U. Prause, and M. Schiodt. 1986.
The Copenhagen criteria for Sjögren's syndrome. Scand. J. Rheumatol. 61(Suppl):19-21.

9. Bunn, C. C., A. E. Gharavi, and G. R. V. Hughes. 1982. Antibodies to extractable nuclear antigens in 173 patients with DNA-binding positive SLE: an association between antibodies to RNP and Sm antigens observed by counterimmunoelectrophoresis. J. Clin. Lab. Immunol. 8:13-17.

10. Clark, G., M. Reichlin, and T. B. Tomasi. 1969. Characterization of a soluble cytoplasmic antigen reactive with sera from patients with systemic lupus erythematosus. J. Immunol. 102:117-122.

11. Kurata, N., and E. M. Tan. 1976. Identification of antibodies to nuclear acidic antigens by counterimmunoelectrophoresis. Arthritis Rheum. 19:574-580.

12. Gerli, R., A. Bertotto, F. Spinozzi, C. Cernetti, F. Grignani, and P. Rambotti. 1986. Phenotypic dissection of cord blood immunoregulatory T-cell subsets by using a two-color immunofluorescence study. Clin. Immunol. Immunopathol. 40:429-435.

13. Gillis, S. M., M. M. Germ, W. Ou, and K. A. Smith. 1978. T cell growth factor: parameters of production and a quantitative microassay for activity. J. Immunol. 120:2027-2033.

14. Maniatis, T., E. F. Fritsch, and J. Sambrook. 1982. Molecular Cloning. A Laboratory Manual. Cold Spring Harbor Laboratory. Cold Spring Harbor, NY. 545 pp.

15. Gerli, R., A. Bertotto, S. Crupi, C. Arcangeli, I. Marinelli, F. Spinozzi, C. Cernetti, P. Angelella, and P. Rambotti. 1989. Activation of cord $\mathrm{T}$ lymphocytes. I. Evidence for a defective $\mathrm{T}$ cell mitogenesis induced through the CD2 molecule. J. Immunol. 142:2583-2589.

16. Breitmeyer, J. B., J. F. Daley, H. B. Levine, and S. F. Schlossman. 1987. The T11 (CD2) molecule is functionally linked to the $\mathrm{T} 3 / \mathrm{Ti} \mathrm{T}$ cell receptor in the majority of $\mathrm{T}$ cells. J. Immunol. 139:2899-2905.

17. Brown, M. H., D. A. Cantrell, G. Brattsand, M. J. Crumpton, and M. Gullberg. 1989. The CD2 antigen associates with the T-cell antigen receptor $\mathrm{CD} 3$ antigen complex on the surface of human $\mathrm{T}$ lymphocytes. Nature (Lond.). 339:551-553.

18. Dauphinée, M. J., Z. Tovair, A. Ballester, and N. Talal. 1989. The expression and function of CD3 and CD5 in patients with primary Sjögren's syndrome. Arthritis Rheum. 32:420-429.

19. Weiss, A., J. Imboden, D. Shoback, and J. Stobo. 1984. Role of T3 surface molecules in human T-cell activation: T3-dependent activation results in an increase in cytoplasmic free calcium. Proc. Natl. Acad. Sci. USA. 81:4169-4173.

20. Hara, T., and S. M. Fu. 1985. I. Monocyte-independent activation and proliferation induced by anti-T3 monoclonal antibodies in the presence of tumor promoter 12-o-tetradecanoyl phorbol-13-acetate. J. Exp. Med. 161:641-656.

21. Nel, E. A., M. W. Wooten, and R. M. Galbraith. 1987. Molecular signaling mechanisms in T-lymphocyte activation pathways: a review and future prospects. Clin. Immunol. Immunopathol. 44:167186.

22. Imboden, J. B., and J. D. Stobo. 1985. Transmembrane signalling by the $T$ cell antigen receptor. Perturbation of the T3-antigen receptor complex generates inositol phosphates and releases calcium ions from intracellular stores. J. Exp. Med. 161:446-457.

23. Tsien, R. Y., R. Pozzan, and T. J. Rink. 1982. T cell mitogen cause early changes in cytoplasmic free $\mathrm{Ca}^{++}$and membrane potential in lymphocytes. Nature (Lond.). 295:68-71.

24. Slade, J. D., and B. Hepburn. 1983. Prednisone induced alterations of circulating lymphocyte subsets. J. Lab. Clin. Med. 101:479487.

25. Hollander, N., E. Pillemer, and I. L. Weissman. 1981. Effect of Lyt antibodies on T-cell functions: augmentation by anti-Lyt-1 as opposed to inhibition by anti-Lyt-2. Proc. Natl. Acad. Sci. USA. 78:1148-1151.

26. Logdberg, L., and E. M. Shevach. 1985. Role of the Lyl antigen in interleukin 1 -induced thymocyte activation. Eur. J. Immunol. 15:1007-1013. 
27. Ceuppens, J. L., and M. L. Baroja. 1986. Monoclonal antibodies to the CD5 antigen can provide the necessary second signal for activation of isolated resting T cells by solid-phase-bound OKT3. J. Immunol. 137:1816-1821.

28. Matsuyama, T., P. Anderson, J. F. Daley, S. Schlossman, and C. Morimoto. 1988. $\mathrm{CD}^{+} \mathrm{CD}^{+} 5 \mathrm{R}^{+}$cells are preferentially activated through the CD2 pathway. Eur. J. Immunol. 18:1473-1476.

29. Sato, K., N. Miyasaka, K. Yamaoka, M. Okuda, J. Yata, and K. Nishioka. 1987. Quantitative defect of CD4+2H4+ cells in systemic lupus erythematosus and Sjögren's syndrome. Arthritis Rheum. 30:1407-1411.

30. Kitas, G. D., M. Salmon, M. Farr, J. S. H. Gaston, and P. A. Bacon. 1988. Deficient interleukin 2 production in rheumatoid arthritis: association with active disease and systemic complications. Clin. Exp. Immunol. 73:242-249.

31. Flescher, E., T. L. Bowlin, A. Ballester, R. Houk, and N. Talal. 1989. Increased polyamines may downregulate interleukin 2 production in rheumatoid arthritis. J. Clin. Invest. 83:1356-1362.

32. Tan, E. M. 1989. Antinuclear antibodies: diagnostic markers for autoimmune diseases and probes for cell biology. Adv. Immunol. 44:93-151.

33. Pease, C. T., W. Shattles, P. J. Charles, P. J. W. Venables, and R. N. Maini. 1989. Clinical, serological, and HLA phenotype subsets in Sjögren's syndrome. Clin. Exp. Rheumatol. 7:185-190.

34. Moutsopoulos, H. M., T. M. Chused, D. L. Mann, J. H. Klippel, A. S. Fauci, M. M. Frank, T. J. Lawley, and M. I. Hamburger. 1980. Sjögren's syndrome (sicca syndrome): current issues. Ann. Intern. Med. 92:212-226.
35. Chisholm, D. M., and D. K. Mason. 1968. Labial salivary gland biopsy in Sjögren's disease. J. Clin. Pathol. (Lond.). 21:656-660.

36. Adamson, T. C., R. I. Fox, D. M. Frisman, and F. V. Howell. 1983. Immunohistologic analysis of lymphoid infiltrates in primary Sjögren's syndrome using monoclonal antibodies. J. Immunol. 130:203-208.

37. Fox, R. I., and A. N. Theofilopoulos. 1985. Production of interleukin 2 (IL 2) by salivary gland lymphocytes in Sjögren's syndrome. Detection of reactive cells by using antibody directed to synthetic peptides of IL 2. J. Immunol. 135:3109-3115.

38. Malone, D. G., S. M. Wahl, M. Tsokos, H. Cattell, J. L. Decker, and R. L. Wilder. 1984. Immune function in severe, active rheumatoid arthritis. J. Clin. Invest. 74:1173-1185.

39. Haraoui, B., R. L. Wilder, D. G. Malone, J. B. Allen, I. M. Katona, and S. M. Wahl. 1984. Immune function in severe, active rheumatoid arthritis. A relationship between depressed peripheral blood mononuclear cell proliferation to soluble antigens and mononuclear cell subset profiles. J. Immunol. 133:697-701.

40. Gerli, R., A. Bertotto, P. Rambotti, P. Barbieri, M. L. Ciompi, and S. Bombardieri. 1988. T cell immunoregulation in rheumatoid synovitis. Arthritis Rheum. 31:1075-1076.

41. Gerli, R., S. Darwish, L. Broccucci, V. Minotti, F. Spinozzi, C. Cernetti, A. Bertotto, and P. Rambotti. 1988. Analysis of CD4-positive T cell subpopulation in sarcoidosis. Clin. Exp. Immunol. 73:226-229.

42. Gerli, R., S. Darwish, L. Broccucci, F. Spinozzi, and P. Rambotti. 1989. Helper-inducer $T$ cells in the lungs of sarcoidosis patients. Analysis of their pathogenic and clinical significance. Chest. 95:811816. 